\title{
O POSITIVISMO COMO OBSTÁCULO EPISTEMOLÓGICO À PRODUÇÃO DO CONHECIMENTO JURÍDICO: O DOGMATISMO E SUAS CONSEQUÊNCIAS PARA A FORMAÇÃO DO JURISTA
}

\section{LEGAL POSITIVISM AS EPISTEMOLOGICAL OBSTACLE TO LEGAL KNOWLEDGE PRODUCTION: DOGMATISM AND ITS CONSEQUENCES TO THE JURIST ACADEMIC EDUCATION}

\author{
${ }^{1}$ Tatiana Mareto Silva \\ ${ }^{2}$ Elda Coelho de Azevedo Bussinguer
}

\section{RESUMO}

O ensino jurídico, no Brasil, adotou uma postura técnico-legalista na qual o aluno é treinado para ler e compreender leis escritas, reduzindo o Direito a essa operação, exclusivamente. Considerando os obstáculos epistemológicos identificados por Gaston Bachelard, e considerando a forma que o ensino jurídico se faz no ambiente acadêmico, o presente trabalho propôs uma reflexão do ensino do Direito sob a ótica da dogmática positivista, identificando a acriticidade da formação do profissional e formação idealista e simplista que dificulta a resolução de problemas sociais complexos, como situações de necessário enfrentamento para a reformulação do modelo de ensino jurídico.

Palavras-chave: Obstáculos epistemológicos, Ensino jurídico, Dogmatismo

\begin{abstract}
Legal education, in Brazil, embraced a tecnical-legalist attitude, in which students are trained to read and understand written law, reducing Right exclusively to this operation. Considering the epistemological obstacles identified by Gaston Bachelard, and considering how legal education happens in Brazilian academies, this essay proposed a reflexive approach of Right education through positive dogmatism, identifying the production of a non-critical and technicist professional and the idealistic and simplistic training which makes difficult the resolution of social complex questions, as problems of necessary coping to reformulate legal education.
\end{abstract}

Keywords: Epistemological obstacles, Legal education, Dogmatism

\footnotetext{
${ }^{1}$ Doutoranda em Direitos e Garantias Fundamentais na Faculdade de Direito de Vitória - FDV Espírito Santo (Brasil). Professora do Centro Universitário São Camilo, Espírito Santo (Brasil).

E-mail:tmareto@gmail.com

${ }^{2}$ Doutora em Bioética pela Universidade de Brasília - UNB, Distrito Federal (Brasil). Professora da Faculdade de Direito de Vitória - FDV, Espírito Santo (Brasil). E-mail: elda.cab@gmail.com
} 


\section{INTRODUÇÃO}

A discussão sobre o ensino superior está bastante viva no meio acadêmico e na sociedade, principalmente no tocante ao ensino jurídico e o crescimento do número de cursos de Direito ocorrido no Brasil em aproximadamente duas décadas - em 1995 havia 165 faculdades de Direito e, em 2010, esse número chegou a 1.284, um crescimento de $778 \%$ (GIESELER, 2015). Esses números refletem excesso de profissionais jurídicos no mercado, com dados da Ordem dos Advogados do Brasil indicando que tínhamos, em 2008, em média, 1 advogado para 322 habitantes (VEJA, 2016). Com o abundância de cursos de Direito e o grande número de bacharéis formados a cada ano, a preocupação com a qualidade do ensino jurídico está constantemente em foco, principalmente frente ao diagnóstico do fraco desempenho dos recém formados no Exame Unificado de Ordem (BIAZZI, 2013).

Mesmo considerando que a aprovação em Exame de Ordem não é o melhor indicador para se 'medir' a qualidade do ensino jurídico, não podemos desconsiderá-lo por completo, uma vez a relevância da própria Ordem dos Advogados em insistentes tentativas de melhoria do ensino jurídico. Porém, o uso da aprovação do Exame de Ordem como indicador nos remete a outro possível problema, que é a padronização dos cursos de Direito visando meramente a aprovação do bacharel em concursos públicos, que realizam a seleção por meio de provas de memorização que prestigiam exclusivamente o conteúdo objetivo, sem qualquer valoração do senso e análise críticos do examinando (STRECK, 2014).

Essa breve análise da situação do ensino jurídico no Brasil apenas ilustra o cenário das academias do Direito no Século XXI - um debate constante entre qualidade e quantidade, entre formação e preparação; uma discussão permanente sobre os reais objetivos de um curso de Direito e o tipo de profissional que se espera saindo dos bancos das faculdades. A problemática se situa na constatação de que o ensino jurídico é dogmático-legalista, uma vez entendermos a academia como um dos mais profícuos espaços para a produção do conhecimento jurídico como ciência, partindo dos estudos de Gaston Bachelard sobre os questionamentos: como o dogmatismo do ensino jurídico pode produzir obstáculos epistemológicos para o conhecimento jurídico e sua construção, e como esses obstáculos podem influenciar a formação dos juristas? 
Para a análise proposta, iniciamos com a compreensão do que Gaston Bachelard entende por obstáculos epistemológicos e como esses obstáculos interferem na formação do espírito científico. Nessa primeira parte, abordaremos o que é ciência e como ela se forma, bem como a relevância da teoria de Bachelard para o pensamento científico. Em seguida, trouxemos o aporte teórico sobre o Positivismo e a dogmática e sua justificativa para o estudo, considerando que o ensino jurídico Brasileiro segue uma tradição dogmática positivista. Apresentamos os principais teóricos do Positivismo e sua conexão com a dogmática jurídica.

Por fim, analisamos o panorama do ensino jurídico no Brasil, a evolução teórica do modelo de ensinar Direito e sua aplicação prática para o rompimento dos modelos tradicionais nas academias jurídicas, bem como o quanto essa dogmática positivista pode significar obstáculos epistemológicos à ciência e identificá-los dentro de uma perspectiva crítica para o ensino do Direito.

\section{CONSIDERAÇÕES SOBRE OS OBSTÁCULOS EPISTEMOLÓGICOS}

O conhecimento científico não é o único existente, não obstante sua categorização como conhecimento verdadeiro, principalmente durante o período . Nesse mesmo sentido o define Horácio Wanderlei Rodrigues (2005, p. 06) - o conhecimento científico é o tradicionalmente tido como verdadeiro e obtido por método científico. Nesse sentido, afirma que

\footnotetext{
todo conhecimento deve ser visto como construção e reconstrução, pelo ser humano, de um determinado objeto ideal, natural ou cultural. Em razão disso, é sempre produção, não a captação contemplativa de qualquer essência. $\mathrm{O}$ ser humano só conhece a realidade na medida em que a cria.
}

Conhecimento, portanto, não é dado ou posto, mas construído. A compreensão do conhecimento científico - a epistemologia - pode ser entendida, sucintamente, como uma teoria do conhecimento. A epistemologia que tomamos como base é aquela desenvolvida nos estudos de Gaston Bachelard (1996) e sua teoria dos obstáculos epistemológicos para explicar a formação do espírito científico. Nessa teoria, Bachelard identifica que o progresso da ciência precisa da colocação de obstáculos para a formação do conhecimento, que seriam intrínsecos ao próprio ato de conhecer, à ciência. 
Barbosa (2010, p. 91) sintetiza o entendimento de Barchelard de que a ciência é fenomenotecnia, definida como um "racionalismo aplicado", ou seja, não podemos mais entender o produto da ciência como resultado de observações do real que se apresenta, pois ele não contribui para a construção de nada novo. Precisamos de aparelhos e técnicas complexas e elaboradas para observarmos elementos que não estão visíveis ao olho humano, mas que têm contribuição relevante para a produção científica.

O que são, então, os obstáculos epistemológicos? Gaston Bachelard entende que o pensamento científico precisa de obstáculos para a sua construção, principalmente porque a construção do novo requer a destruição do velho (BACHELARD, 1996, p. 17). Apenas com a compreensão de que a ciência só se forma com a superação de obstáculos é que podemos encontrar o verdadeiro espírito científico, portanto, é importante identificar os obstáculos para que eles não se tornem empecilhos intransponíveis para a produção do pensamento científico.

Os obstáculos epistemológicos estão postos para o conhecimento científico pois eles dificultam e impedem a (re)construção de novos saberes, de novos produtos. Entre eles, estão o conhecimento geral e o risco das interpretações generalizantes, a observação primeira, que fornece imagens fáceis, pitorescas e que acomodam o cientista, e o conhecimento unitário e pragmático, que reduz e condensa conceitos e percepções em meio à heterogeneidade e multiplicidade de objetos (BACHELARD, 1996).

Bachelard (1996, p. 18) coloca a opinião como o primeiro obstáculo a ser superado, pois ela "não pensa". Não se faz ciência com opiniões sobre aquilo que não se conhece profudamente, sobre o que não entendemos bem. Para pensarmos cientificamente, temos que pensar problematicamente, formulando questões e buscando suas respostas. "Para todo o espírito científico, todo conhecimento é resposta a uma pergunta. Se não há pergunta, não pode haver conhecimento científico. Nada é evidente. Nada é gratuito. Tudo é construído" (BACHELARD, 1996, p. 18).

Ele critica o fato de que os filósofos considerem como base de toda ciência as generalizações. Essas generalizações serviriam como verdades intocáveis que esclareceriam todo o resto, porém elas se constituem em obstáculos pois não suscitam mais pergunta alguma. Quanto mais claras estão postas as coisas em razão das generalizações, menos perguntas fazemos e, portanto, menos ciência produzimos (BACHELARD, 1996, p. 70). 
Nesse momento, Gaston Bachelard faz também uma crítica à pedagogia do ensino das ciências, pois a reprodução das regras gerais, tão claras e objetivas, retiram a vontade de se estudar os fenômenos de forma mais profunda. O conhecimento posto apressadamente, com base em tabelas preenchidas pela simples observação do natural (que Bachelard também entende como obstáculo epistemológico), forma um conhecimento estático que, em determinado momento, emperrará a pesquisa científica (BACHELARD, 1996, p. 72).

A atração do cientista pela generalização leva à ausência de questionamento daqueles conceitos prontos e pré-determinados como verdades científicas. Para Bachelard (1996, p.84), "o pensamento pré científico não limita seu objeto: mal conclui uma experiência específica, já procura generalizá-la aos mais variados domínios". Por muitas vezes, essas aplicações podem ser incorretas ou inadequadas, e tornam o espírito científico débil, fraco, sem buscar conhecer profundamente os fenômenos que, supostamente, já são conhecidos por estarem simplesmente classificados - o que consiste em uma crítica ao baconismo e às tabelas científicas.

A clara crítica posta ao empirismo científico e suas generalizações mostra que esse é um obstáculo epistemológico a ser superado na formação do espírito científico. Em contrapartida, Bachelard identifica outro obstáculo de sérias implicações na ciência, que ele denomina de conhecimento unitário e pragmático. O perigo da unidade está na pressa em que se descarta a dualidade e na forma em que os problemas são formulados em um mesmo plano quando deveriam ser formulados em planos distintos. A unidade sugere harmonia, homogeneidade, identidade entre conceitos e problemas que foram colocados sob a mesma generalização unitária sem uma análise mais profunda de seus objetos.

Esse obstáculo para a formação do pensamento científico também se consubstancia nas generalizações utilitárias, que, realizadas com base em conceitos genéricos e induções duvidosas, sustentariam a aplicação de regras para uma generalidade de objetos sem o devido cuidado da experiência científica - o que Bachelard (1996, p. 117) chama de "generalização exterma".

A contribuição da obra de Bachelard não se resume a essa singela exposição sobre os obstáculos epistemológicos consistentes na generalização e redução unitária, porém, são esses os obstáculos que analisamos em conjunto com a dogmática positivista e o ensino jurídico, sobre as quais passamos a discorrer. 


\section{O POSITIVISMO CIENTÍFICO E JURÍDICO}

Em meio ao caos e a desordem social que marcaram o período da Revolução Industrial, na transição dos Séculos XVIII e XIX, situa-se historicamente o Positivismo como corrente científica, que tem em Augusto Comte sua expoência original. O Positivismo, como corrente de pensamento, propõe que o método científico rigorosamente baseado na experimentação é o único capaz de produzir conhecimentos científicos válidos e verdadeiros - verdade e certeza. Comte compreendia que todo conhecimento humano passava por três estágios, sendo eles o teológico, o metafísico e o positivo, o que foi denominado de "lei dos três estágios" (COMTE, 1978). O estágio teológico é fictício e os fenômenos observados são um produto do sobrenatural. Nesse estágio, predominam as explicações divinas aos acontecimentos da natureza. O segundo estágio, metafísico, é abstrato e, segundo Comte, servia apenas como transição entre o primeiro e o terceiro. Durante o estágio metafísico as explanações sobrenaturais não são mais aceitas pelo homem, porém ele ainda não atingiu o espírito científico positivo.

É no terceiro estágio do pensamento, segundo Comte, que o homem deixa de estudar as causas - o que é atribuído à filosofia metafísica - para buscar as leis que se relacionam com os fenômenos (COMTE, 1978). Aqui residiria a verdadeira ciência e sua busca às verdades absolutas e incontestáveis. O pensamento positivista de Comte é abrangente e classificatório conforme a complexidade dos fenômenos que cada ciência se propõe a investigar. Assim, temos a matemática e a astronomia como ciências de objetos menos elaborados e a sociologia como ciência mais complexa. Todo estudo científico deve, para ser válido, seguir o rigoroso método positivo de experimentação, o que significava que o comportamento humano e social pode ser reduzido a leis gerais e, consequentemente, previsto e esperado (COMTE, 1978).

O positivismo também preconiza o caráter contínuo e acumulativo do conhecimento científico, pois o que se adquire por meio do estado positivo não mais volta atrás - o que acontece com a evolução do homem e das sociedades é o crescimento contínuo do conhecimento por meio de novas experiências e observações (COMTE 1978). O positivismo tem como característica a universalização generalizante, que determina que a unidade lógica (à qual foi reduzida o objeto de experimentação) obedeça sempre à mesma lei - o que desconsidera a diversidade e a especificidade de objetos e disciplinas. 
O caráter dogmático e universalizante da teoria de Comte passou a dominar entre a ciência na Europa. No Século XX, mais precisamente entre os anos de 1920 e 1940, em Viena, Aústria, um grupo de pensadores, pautados nas ideias positivistas, formou o que se denominou posteriormente de Círculo de Viena, para estudar e debater questões voltadas para a ciência. O positivismo do Círculo de Viena, denominado Positivismo Lógico ou Neopositivismo, tem bases empiristas e pauta-se na concepção que renega tudo que é metafísico. Moritz Schilick e Rudolf Carnap, em diferentes obras e análises, consideram que as questões metafísicas são meras proposições sem sentido, um amontoado de palavras incompreensíveis. Essa percepção é claramente expressa no manifesto do Círculo, denominado "A concepção científica do mundo" e escrito por Carnap, Neurath e Hahn: "A filosofia metafísica é recusada pela concepção científica do mundo" (CARNAP, NEURATH, HAHN, 1986, p. 11).

A compreensão de ciência do Círculo de Viena é muito próxima daquela de Augusto Comte, não obstante mais empírica. Ela entende que o conhecimento é científico e válido apenas quando submetido a um método de verificação e experimentação, excluindo obrigatoriamente o conhecimento a priori - que entendem impossível. Nesse contexto, o verificacionismo é marca registrada do Positivismo e do Positivismo Lógico (Neopositivismo), ambos considerando a verdade e a ciência decorrentes da experimentação. Os integrantes do Círculo entendem a concepção científica do mundo considerando-a como empirista e positivista, caracterizada pela aplicação de um méotodo a análise lógica (CARNAP, NEURATH, HAHN, 1986, p. 12).

O Neopositivismo, que se propôs também a "purificar" as ciências sociais da metafísica e tudo que não seja estritamente científico, à luz de seus conceitos, influenciou diretamente uma das concepções mais relevantes do Direito, o Positivismo Juridico. Como explica Bobbio (1995, p. 135), "o positivismo jurídico nasce do esforço de transformar o estudo do direito numa verdadeira e adequada ciência que tivesse as mesmas características das ciências físico-matemáticas, naturais e sociais".

A Teoria Pura de Kelsen, formulada com base no positivismo científico, é epistemológica, ou seja, buscou apresentar um método para a ciência jurídica quando havia muita confusão acerca do tema e se considerava, inclusive, se o Direito não deveria ser absorvido por outras ciências, como a sociologia ou a filosofia. Ou seja: “Quer isto dizer 
que ela pretende libertar a ciência jurídica de todos os elementos que lhe são estranhos. Esse é o seu princípio metodológico fundamental” (KELSEN, 1998, p. 1).

As bases da teoria kelseniana são as mesmas do Neopositivismo, tanto no sentido de tentar reduzir ao máximo o objeto de estudo da ciência jurídica - no caso, à norma, quanto no sentido de buscar conceitos gerais universalizantes que se aplicariam a todo ordenamento jurídico. Ou seja, a Teoria Pura do Direito é uma teoria positivista do Direito e uma das mais polêmicas, principalmente por sua característica reducionista. Mas, no que consiste a proposta kelseniana para o Direito? Em primeiro lugar, levantamos a necessidade de que o conhecimento jurídico seja neutro, conectando a Teoria Pura à neutralidade axiológica de Comte. Neutro porque não se ocupa de relações entre a norma e valores quaisquer, o objeto de estudo do conhecimento jurídico é pura e simplesmente a norma jurídica (KELSEN, 1998, p. 50).

Da mesma forma que Comte coloca o estudo da sociedade com base na observação da ordem (estática) e do progresso (dinâmica), Kelsen enxerga no Direito uma teoria jurídica estática, que se refere ao ordenamento jurídico, ao sistema normativo, e uma dinâmica, que é o Direito sendo produzido e posto em aplicação. Para Kelsen (1998), no entanto, a aplicação do Direito só tem relevância para a ciência jurídica no referir-se às normas.

Uma posição interessante da Teoria Pura é a forma como ela se coloca como uma teoria voltada exclusivamente para doutrinadores, ou seja, os cientistas jurídicos. Kelsen deixa claro que Direito e ciência jurídica não se devem confundir ou misturar, e que esse equívoco frequente pode causar distorções de compreensão e interpretação da teoria (KELSEN, 1998). Nesta feita, Kelsen entende a ciência jurídica como meramente descritiva, enquanto a autoridade jurídica, que efetivamente aplica o Direito, tem atividade prescritiva.

A Teoria Pura também pressupõe um distanciamento entre o Direito e a Moral, uma vez que Kelsen repudia a ideia de que o Direito precise de um conteúdo Moral para se legitimar. Se a pureza do Direito consiste em sua neutralidade e universalização, Kelsen não consegue conceber uma "moral generalizante" que consiga se relacionar com a norma jurídica generalizante. "Se supusermos que o Direito é, por sua essência, moral (tem caráter moral), então não faz qualquer sentido a exigência - feita sob o pressuposto da existência de um valor moral absoluto - de que o Direito deve ser moral" (KELSEN, 1998, p. 47). 
A relação entre Direito e Moral também forçaria a ciência jurídica a possuir uma característica justificadora, indo de encontro à teoria kelseniana que entende a ciência do Direito como meramente descritiva, como já anteriormente abordamos. Não se chega a negar a possibilidade de que o Direito e a Moral tenham qualquer relação, já que as normas morais também são normas sociais, porém estas não contém qualquer coercitividade, essencial à norma jurídica. "A ciência exclui do próprio âmbito os juízos de valor, porque ela deseja ser um conhecimento puramente objetivo da realidade, enquanto os juízos em questão são sempre subjetivos (ou pessoais) e consequentemente contrários à exigência da objetividade" (BOBBIO, 1995, p. 135).

Kelsen esforçou-se para desenvolver uma teoria afastada de ideologias políticas, respeitando as especificidades do Direito e sua legalidade (termo utilizado expressamente no prefácio à $1^{\mathrm{a}}$ edição da obra Teoria Pura do Direito). Por si só já se configura que a pureza pretendida por Kelsen significaria o afastamento da ciência jurídica de diversos fatores sociais ou naturais que não estivessem objetivamente inseridos na norma. Ele não foi, no entanto, o único pensador positivista do Direito. Podemos mencionar, com relevo, $\mathrm{H}$. L. A. Hart com sua obra "O conceito de Direito", cuja proposta foi apresentar "uma teoria do direito que fosse ao mesmo tempo geral e descritiva" (HART, 2009, p. 309).

Hart define sua teoria como geral, por não se filiar a nenhum sistema ou cultura específicos e por traçar linhas gerais e universalizantes que pudessem servir a qualquer ordenamento jurídico, que consubstanciassem uma teoria geral do Direito. Da mesma forma, entende que sua teoria é descritiva por ser "moralmente neutra" e "sem fins de justificativa" (HART, 2009, p. 309). Não obstante a conexão semântica e conceitual que observamos na teoria positivista kelseniana especificamente, e até mesmo no Positivismo Jurídico como um todo, Bobbio tem outra concepção de Direito Positivo e não considera que ele seja relacionado, nos dias atuais, com o Positivismo científico. "A expressão 'positivismo jurídico' deriva da locução direito positivo contraposta àquela de direito natural" (BOBBIO, 1995, p. 15).

Em verdade, os pensadores positivistas entendem que o direito positivo se contrapõe ao direito natural, e que a codificação do direito se relaciona diretamente ao Positivismo Jurídico, uma vez que esta corrente reduz todo conhecimento científico do Direito à norma. Esse processo de codificação decorre do abandono ao jusnaturalismo, cuja maior crítica aconteceu na Alemanha, mais precisamente dentro do movimento do 
historicismo jurídico de Savigny. Foi Thibaut, no entanto, que defendeu iniciamente o movimento da codificação do direito na Alemanha (BOBBIO, 1995).

Já na Inglaterra, a common law não impediu que o Positivismo Jurídico se desenvolvesse. Austin, por exemplo, coloca em comparação o direito dos juízes e o direito dos legisladores, entendendo que os juízes não podem agir senão dentro daquilo que lhe confere o soberano (BOBBIO, 1995, p. 109), bem como entendendo que o direito judiciário deveria ser substituído pelo codificado (BOBBIO, 1995, p.112).

Neste sentido, Radbruch, também dentro de uma proposta Positivista para o Direito, trata de diferenciar a justiça para corroborar com o pensamento de Austin: “A Justiça enquanto parâmetro do Direito Positivo - a juridicidade - da Justiça enquanto idéia anterior e superior à lei - Justiça em sentido estrito. Aquela é a Justiça do Juiz, esta a Justiça do legislador. Apenas este último aspecto da Justiça interessa-nos neste trabalho" (RADBRUCH, 2002, p. 24). O que tem validade e importa ao Positivismo Jurídico é a norma, sua validade e tudo aquilo determinado pela norma - inclusive o ordenamento jurídico. Interessa aos positivistas a segurança jurídica que se pode obter com o Direito em seu viés positivo, a "segurança do direito em si mesmo" (RADBRUCH, 2002, p. 28), que só poderia ser obtida pelo Positivismo Jurídico.

Uma vez traçados os contornos do Positivismo Jurídico, é importante conectá-lo com o que se denomina dogmática jurídica, que se aproxima mais do objeto principal deste trabalho. Essa conexão está bem clara no texto de Luis Alberto Warat, que afirma: “[...] La dogmatica juridica se vincula directamente con el positivismo, limitando su función a la interpretación de la ley, mediante el método denominado exegético [...]"1 (WARAT, 2004, p. 154).

Tércio Sampaio Ferraz Junior também conecta dogmática e Positivismo Júridico ao afirmar que o Direito positivo e o crescente aumento da importância da lei para o Direito foram fundamentais para a consolidação da autonomia da dogmática (FERRAZ JUNIOR, 1980, pp. 68-69). Dessa forma, por mais que a dogmática, em uma compreensão científica, seja mais abrangente do que o Positivismo Jurídico, não podemos deixar de correlacioná-los de forma intrínseca em razão do papel que a lei escrita assumiu, desde o Século XIX, para o Direito e para a própria dogmática. Usamos o termo dogmática-positivista para ilustrar

\footnotetext{
1 Em tradução livre, “[...] A dogmática jurídica se vincula diretamente com o positivismo, limitando sua função à interpretação da lei, mediante o método denominado exegético $[\ldots]$ ”
} 
com mais precisão essa conexão a dogmática jurídica é, senão, o que se entende por ciência do Direito, na tentativa de construi-la sistematicamente, sem qualquer juízo de valor, formalisticamente (WARAT, 2004; ADEODATO, 2002). Considerando que o dogma da dogmática jurídica é a própria norma, ela também se torna o fio condutor para a compreensão tanto do Positivismo quanto da dogmática, ambos por ela centrados e limitados.

\section{O DOGMATISMO E O LEGALISMO NO ENSINO JURÍDICO CONTEMPORÂNEO}

Antes de passarmos à identificação de obstáculos epistemológicos na formação do conhecimento do Direito, é importante traçarmos um breve panorama do ensino jurídico no Brasil. Em 2010, a Ordem dos Advogados do Brasil (OAB) divulgou que o Brasil possuía mais cursos de Direito do que todos os outros países do globo terrestre, somados (OAB, 2010). Nessa época, havia 1.240 cursos de Direito no Brasil, colocando anualmente, no mercado, profissionais que exercerão diversas profissões jurídicas e que serão responsáveis pela aplicação do Direito e evolução da ciência jurídica.

Em uma perspectiva histórica, já relevamos que o ensino jurídico nacional assumiu características tecnicistas, com objetivo de reproduzir conceitos e sem apego à formação crítica (FRANCISCHETTO, 2011). O curso de Direito não surgiu, no Brasil, para formar juristas, mas políticos - pessoas que precisavam de títulos para se manter em posições sociais de relevo. Nessa perspectiva, não havia qualquer necessidade de se formar um profissional crítico e comprometido com as transformações da realidade, uma vez que o objetivo era exatamente o inverso: a manutenção das estruturas de poder e do status quo vigente (OLIVEIRA, 2010).

Nesse sentido, consolidou-se, nos cursos de Direito, a forma jesuítica de ensinar - o professor, centro do processo, passava conhecimentos aos alunos, que tinham como única tarefa memorizá-los adequadamente. O sucesso desse modelo de ensino seria verificado com testes que conferiam se a memorização foi eficiente, sem exigir qualquer construção do aluno e sem aproveitar seus conhecimentos prévios ou vivência social. Essa proposta de aula expositiva, na qual o professor palestra e o aluno é entendido como uma tela em branco capaz de gravar em si mesmo um amontoado de conceitos que não necessariamente fazem sentido prático, foi criticada por Freire (2007), que a denominou "educação bancária", na qual o professor depositaria informação no aluno (o banco). 
Esse cenário levou o ensino do Direito no Brasil a assumir uma postura dogmática, positivista e legalista. $\mathrm{O}$ estudante, para adentrar em uma academia jurídica, realiza uma prova de seleção e, caso aprovado, insere-se em um universo de códigos, leis e normas do qual está fadado a nunca mais sair - a não ser que desista de qualquer profissão jurídica. Durante todo o curso de Direito, os estudantes são treinados para ler a norma e compreendê-la dentro de uma forma esperada. Deseja-se, nas academias, que o aluno decore artigos de lei para que possa obter sucesso nas avaliações, sua grande maioria em formato prova, com questões de múltipla escolha.

Para Bussinguer (2012), é o conservadorismo das próprias profissões jurídicas que empurra o ensino do Direito para um esquema formalista e no qual a norma supera a realidade, com prevalência da relação vertical entre professor e aluno e a compreensão de que o conhecimento possa ser transmitido. Apesar da manutenção desse modelo até a contemporaneidade, ele vem deixando de ser suficiente, principalmente em razão de novas exigências - dos alunos, do mercado, da complexidade da sociedade. O Direito se modifica, deixando bases positivistas, incorporando valores e princípios, e o ensino que forma meros leitores de códigos não mais atende as demandas de uma sociedade plural.

Como releva José Geraldo de Sousa Júnior (2011, p. 58), a manutenção dessa situação pode se escorar no fato de que o professor de Direito, em um passado recente, era apenas um jurista, e que "o exercício da docência jurídica se resumia à reprodução da prática de desempenho do profissional, que se tornava modelo para os demais, que se inspiravam na sua experiência." Ou seja, o professor, nas academias de Direito, "relê para seus alunos as leituras que já fez. Então, ele é um locutor da codificação, ou da doutrina disponível, que é uma reprodução do senso comum, teórico, se quiser, de suas leituras dos códigos [...]" (SOUSA JUNIOR, 2011, p. 58).

Mudanças significativas puderam ser observadas a partir de 1991, com a instalação da primeira Comissão de Ensino Jurídico da Ordem dos Advogados do Brasil, que aconteceu em congresso na cidade de Vitória-ES. Como explica Loussia Musse Felix (2011, p. 144),

o desafio era fazer do então chamado ensino jurídico um instrumental socialmente adequado para uma transição democrática desde um aparato jurídico com fortes características legadas do chamado estado autoritário para a construção de um sistema jurídico mais democrático, eficaz, igualitário e socialmente justo. 
Em 1994, o Ministério da Educação (MEC) publicou a Portaria 1886, resultado dos esforços conjuntos da Comissão de Ensino Jurídico e profissionais do próprio MEC, para tornar obrigatório o desenvolvimento conjugado de atividades de pesquisa, extensão e ensino, bem como da inserção de disciplinas propedêuticas, como filosofia, sociologia e metodologia, nos cursos de Direito (FELIX; SANTOS, 2011). Em 2004, a Resolução 09 do Conselho Nacional de Educação veio regulamentar os cursos de Direito de forma mais ampla e consolidada, determinando também competências e habilidades relevantes para a formação crítica do profissional jurídico. O que observamos, nesse panorama, é que, não obstante o trabalho conjunto de instituições e profissionais voltados para a modificação da forma de ensino do Direito, as regulações normativas vem sendo cumpridas em seu mínimo pelos cursos de Direito espalhados pelo Brasil, que ainda mantém a proposta dogmatista positivista de ensino (STRECK, 2011) e negligenciam a formação dos professores de Direito como um todo (OLIVEIRA, 2010)

Seguindo o entendimento de Tércio Sampaio Ferraz Junior (1980), o ensino jurídico dogmático-positivista conduz o jurista a uma formação fechada e formalista, bem como a dupla abstração inerente à dogmática proporciona um distanciamento dos estudos jurídicos da realidade social. João Maurício Adeodato (2002) traz a autoridade dogmática do professor e as aulas no estilo conferência como características do dogmatismo-positivista do ensino jurídico, para justificar a baixa credibilidade e criticidade do profissional do Direito formado no Brasil. A questão sobre a qual esse trabalho versa é o quanto esse positivismo dogmático do ensino do Direito atravanca ou obstaculiza a formação do pensamento científico jurídico, que, por lógica, dever-se-ia acontecer nas academias. O quanto a pesquisa jurídica e a ciência do Direito podem ser retardadas ou prejudicadas pelo dogmatismo e pelo legalismo que define as escolas de Direito.

\subsection{Obstáculo Epistemológico Teórico: A Acriticiade e Homogeneidade da Ciência Jurídica}

Usamos as características da dogmática trazidas por João Maurício Adeodato (2002) para problematizar e identificar um obstáculo epistemológico à formação do espírito científico: i) a dogmática neutraliza e estabiliza os valores na intenção de manipulálos conforme o seu interesse; ii) a dogmática garante sua estabilidade contra a mutabilidade social afastando-se do fato social; iii) a dogmática jurídica possui independência em relação 
à realidade concreta de forma camuflada e sutil, garantindo assim a crença de que seu sistema decisório é eficaz e não opressivo.

O que se observa sobre a dogmática positivista é que, com sua abstração generalizante, a heterogeneidade social é uma questão ignorada em sua compreensão. A norma tende a igualar, unificar abstratamente o seu objeto para que abranja a maior quantidade de situações possíveis. Em verdade, quanto mais estratificada e complexa for a sociedade, quanto mais complexos forem os conflitos, maior o grau de abstração exigido da dogmática (ADEODATO, 2002, p. 32). Ao se reduzir o ensino do Direito à dogmática positivista, ou seja, ao se reduzir as academias jurídicas à mera leitura e compreensão das leis, dentro dos critérios hermenêuticos apresentados pela própria dogmática, estamos afastando o estudante de Direito do fato social, da realidade concreta, e transportando-o para um "mundo paralelo" no qual a lei se justifica como um fim em si mesma.

Duas consequências para a dogmática-positivista no ensino jurídico brasileiro: a ausência de criticidade livre em relação ao próprio Direito e a redução generalizante do pensamento jurídico em contraste com uma sociedade heterogênea e complexa. Essas consequências se colocam como obstáculos epistemológicos claros à formação do espírito científico jurídico, pois o estudante de Direito não é talhado para questionar e buscar o novo; as academias não buscam o Direito que está nas ruas para sustentar suas bases. O que se verifica é o treinamento dos estudantes, a formação literal de conhecedores e interpretadores de normas, não de questionadores e produtores de conhecimento científico.

Trabalha-se com o sentido comum teórico ao invés do prático. A dupla abstração característica da dogmática-positivista faz com que as regras interpretativas, mesmo que sugiram a crítica, não ultrapassem um limite pré fixado para tal.

O sentido comum teórico sufoca as possibilidades interpretativas. Quando submetido à pressão do novo, (re)age institucionalizando a crítica. Para tanto, abre possibilidades de dissidências apenas possíveis (delimitadas previamente). Ou seja, no interior do sentido comum teórico, permite-se difusamente, (apenas) o debate periférico, mediante a elaboração de respostas que não ultrapassem o teto hermenêutico prefixado (horizonte do sentido). (STRECK, 2007, pp. 30-31)

Está demonstrado o obstáculo epistemológico teórico da acriticidade no ensino jurídico - nas academias não é debate sobre o Direito, não há discordância ou questionamento, apenas reprodução do que se está posto. E, quando há debate, esse está 
dentro dos limites esperados para que ele aconteça. As academias se reduzem à reprodução acrítica do Direito, sem contestar suas bases ou identificar suas contradições.

Quanto à visão homogenizadora da dogmática-positivista, o obstáculo reside no fato de que a complexidade das sociedades e das relações interpessoais da pós modernidade não sustenta mais essa visão generalizante da norma (ADEODATO, 2002), que insiste em ser passada acriticamente nos bancos das academias de Direito.

Um exemplo do quanto a dogmática-positivista afasta o estudante, futuro jurista, da realidade fática e simplifica o que é complexo está em uma das mais relevantes premissas do Estado Brasileiro: todos são iguais perante a lei. A interpretação dogmática para o princípio da isonomia consistente nessa afirmativa é que todas as pessoas devem possuir o mesmo tratamento frente ao Estado - e não apenas ao Poder Legislativo, sem qualquer discriminação. O que essa interpretação ignora, no entanto, é a heterogeneidade da sociedade e a sua complexidade, bem como a histórica presença de grupos excluídos, para os quais a isonomia nada representa.

O exagero dogmatista do ensino jurídico, de cultura manualesca e codicista, faz com que a doutrina se enfraqueça como fonte do Direito, uma vez ter cada menos características críticas, e fortalece um sistema de jurisprudências teratológicas e, por vezes, contraditórias, que derivam de profissionais que não possuem o senso crítico prático formado (STRECK, 2007).

A dogmática pode se justificar, de certa forma, para satisfazer os anseios do estudante que deseja se tornar um profissional do Direito e precisa conhecer e interpretar as leis; tem cunho imediatista (FERRAZ JUNIOR, 2002). Mas não contribuiu para a formação do pensamento científico jurídico, uma vez que engessa e entorpece a busca pelo novo, a crítica e o debate no âmbito das academias.

\subsection{Obstáculo Epistemológico Prático: A Fria Aplicação da Norma e sua Ineficácia para a Resolução dos Conflitos Sociais}

Considerando que o ensino jurídico segue uma metodologia dogmática positivista, e que o futuro jurista que senta nos bancos da academia é treinado para ler e interpretar a norma dentro de uma proposta prescrita previamente, o perfil esperado do profissional jurídico que se forma no Brasil é meramente técnico-legalista. Isso significa um profissional pouco crítico e por vezes incapaz de conectar o que foi absorvido - no nada 
sutil modelo 'esponja' - durante a graduação e o que se apresenta como situação de conflito no fazer jurídico.

Ou seja, os juízes, advogados, promotores, procuradores, delegados, formados dentro de uma proposta dogmático-positivista, são, comumente, incapazes de dar soluções eficazes aos conflitos que se apresentam no mundo real. Como afirma Lênio Streck (2007, p. 32), "[...] os conflitos sociais não entram nos fóruns e nos tribunais graças às barreiras criadas pelo discurso (censor) produzido pela dogmática jurídica dominante."

Essa constatação revela um importante obstáculo epistemológico à ciência do Direito, dessa vez de natureza prática. A ausência de criticidade e o pouco questionamento do sistema, da norma posta, nas academias de Direito, traz como consequência profissionais que estão totalmente desconectados da realidade em seu entorno e tira o Direito das ruas, objetificando- o e tornando-o abstrato a ponto de não ser eficaz para a resolução dos conflitos reais.

É como definiu Luis Alberto Warat (ao afirmar que "a epistemologia tradicional procura resolver, idealmente, as relações conflitantes entre a teoria e a práxis jurídica, ignorando, fundamentalmente, o valor político do conhecimento na práxis." Ao criticar a possibilidade de uma pós-graduação stricto sensu profissionalizante para o Direito, Lenio Streck (2011) reforça a análise de que os cursos de bacharelado já são tecnicistas o bastante e que isso nem mesmo pode ser interpretado de forma positiva, frente os péssimos resultados obtidos por grande parte dos cursos de Direito frente o Exame Nacional da OAB.

Ainda, o dogmatismo positivista acaba por confundir o estudante de Direito em razão dessa abstração pouco objetiva, que possibilita, ao final, muitas interpretações para uma mesma norma. O estudante toma essa variedade de interpretações como opiniões (FERRAZ JUNIOR, 1980; ADEODATO, 2002) e não se forma criativo o suficiente para assumir suas próprias soluções quando na prática profissional. Dessa forma, "[...] a objetividade da prática jurídica se vê prejudicada pela imperícia e perplexidade dos novos profissionais do Direito [...]" (ADEODATO, 2002, p. 44).

A severa crítica de Lenio Streck ao ensino jurídico Brasileiro, objeto de discussões em diversos textos do pesquisador sulista, reside exatamente neste fato, de que o profissional jurídico que sai das academias é um formalista que não consegue se desprender de ideais como a vontade do legislador, ou o sentido estrito da norma. Na visão de Streck, os problemas sociais conseguem ser resolvidos, pela administração da justiça, dentro dos padrões dogmáticos-positivistas ensinados nas academias, porém, quando as 
questões mais complexas se colocam para o jurista, ele não sabe o que fazer ou acaba por tornar inócuo o próprio texto legal ao qual se vincula (STRECK, 2007).

\section{CONCLUSÕES}

Apesar das muitas considerações relacionadas ao ensino do Direito e os obstáculos à formação do espírito científico, as conclusões quanto ao problema posto podem se apresentar óbvias - enquanto as soluções ainda não foram experimentadas em sua integralidade. A evolução da teoria da educação jurídica ${ }^{2}$ no Brasil é grande desde a década de 1990, porém ela ainda não atingiu a prática de forma contundente para modificar o quadro das academias de Direito. A formação dos professores de Direito ainda é desconsiderada por muitas instituições (OLIVEIRA, 2010), sugerindo que a experiência profissional é suficiente para que eles sejam capazes de lecionar nas academias. Os alunos chegam aos bancos das universidades acreditando que o Direito se resume à lei lá encontram professores que aderem a manuais, resumos e outras fórmulas mágicas capazes de simplificar o que é complexo e de idealizar o que deveria ter sentido material (STRECK, 2014).

Nesse paradigma de ensino, a lei não falha, o sistema é justo, seguro e necessário, e o jurista assim é formado para se tornar um profissional enquadrado e apto a reproduzir um discurso de dominação e violência da dogmática jurídica (ADEODATO, 2002; STRECK, 2007). A complexidade das relações sociais e dos problemas que se apresentação para o profissional do Direito não têm espaço nas academias, que se propõem quase que exclusivamente a treinar seus alunos para a realização de provas de concursos públicos, o fetiche de quase todo estudante de Direito.

\footnotetext{
2 Loussia Musse Felix (2011) adota o termo educação jurídica em substituição a ensino jurídico para demonstrar a transição ocorrida desde a formação da primeira Comissão de Ensino Jurídicos da Ordem dos Advogados do Brasil, apresentando que o quadro da educação jurídica prestigia a formação de profissionais críticos e mais desapegados do positivismo legalista.
} 
Essa perspectiva dogmática-positivista impõe uma série de obstáculos epistemológicos à formação do pensamento científico jurídico - obstáculos esses que devem ser suplantados para que a ciência do Direito se faça (BACHELARD, 1996). É apenas com a identificação desses obstáculos e com a sua transposição que vislumbraremos a formação do verdadeiro espírito científico jurídico. A ausência de criticidade e debate dentro das academias, a generalização unificadora das normas e da aplicação do Direito, a falta de conexão da norma com a realidade concreta com a qual terá que lidar o jurista, a necessidade de adequação do próprio Direito à evolução e complexidade da sociedade, entre outros, estão assim postos como obstáculos epistemológicos a serem ultrapassados pelo cientista jurídico.

Como isso será possível, considerando a importância que a dogmática positivista tem como dominação do próprio Estado, é praticamente outro obstáculo a se transpor para uma modificação do paradigma do ensino jurídico no Brasil. Isso porque, de certa forma, as soluções já estão dadas, com regulações específicas para o ensino do Direito e farto material teórico para sustentar uma reformulação do modelo. A Ordem dos Advogados do Brasil fiscaliza as instituições de ensino e exige que os bacharéis realizem exames para o exercício da profissão de advogado; o Ministério da Educação impõe rígida normatização para o ensino superior, com portarias, pareceres e resoluções que objetivam a formação mais humana dos profissionais, a titulação dos professores, a realização de pesquisa nas universidades, o desenvolvimento de competências voltadas para a crítica e a construção do Direito; instituições como Associação Brasileira de Ensino do Direito (ABEDI) e Conselho Nacional de Pesquisa e Pós-Graduação em Direito (CONPEDI) buscam constantemente discutir e produzir conhecimento na área da educação jurídica mas, ainda assim, a prática não consolidou essa busca por um novo modelo.

Uma resposta certamente está na metodologia do ensino do Direito, na forma como as academias tratam o ensino jurídico: é necessário repensar todo um sistema secular de ensino e modificar atitudes e estratégias para tornar a graduação em Direito um espaço real de produção de ciência jurídica. Não estamos falando de uma simples tarefa. Para Luis Alberto Warat (2004), o Direito sequer pode ser ensinado - o filósofo argentino considera que não se aprende por imposição, que as pessoas apenas aprendem aquilo que desejam saber, e que somente uma proposta de ensino pautada no diálogo e na contestação seriam proveitosas nas academias de Direito. O processo de ensino Brasileiro é opressivo 
e desumanizante, faz-nos fugir da realidade e coloca o estudante em uma redoma teórica que não permite qualquer diálogo com o saber comum ou com o quotidiano social.

O mesmo Warat, no entanto, reconhece a importância da dogmática para segurar o cidadão contra eventuais destemperos do Estado. Não é solução para o problema extinguir a dogmática, ultrapassar totalmente o Positivismo Jurídico, e instalar a anarquia normativa que poderia levar a injustiças e incoerências ainda maiores do que a abstração do dogmatismo.

É preciso repensar a forma que se ensina Direito nas academias - ao invés disso, passarmos a produzir Direito. Os espaços precisam ser mais diplomáticos, em que o conhecimento se trabalha transversalmente, interdisciplinarmente, dialogicamente, aproveitando-se o conhecimento prévio e não científico do aluno para a construção do pensamento científico, sem que a autoridade - inexistente - do professor se imponha e se torne uma barreira ao debate. É preciso permitir a crítica ao sistema, à própria lei, trabalhála hermeneuticamente para que ela seja suficiente para a resolução dos conflitos sociais e para que se adeque à complexidade e mutabilidade social.

Uma nova forma de se ensinar Direito é transpor os obstáculos epistemológicos e, consequentemente, produzir o espírito científico jurídico nas academias. Não devemos abolir a dogmática-positivista, mas não podemos nos reduzir a ela.

\section{REFERÊNCIAS}

ADEODATO, João Maurício. Ética e retórica: para uma teoria da dogmática jurídica. São Paulo: Saraiva, 2002.

BACHELARD, Gaston. A formação do espírito científico. Rio de Janeiro: Contraponto, 1996.

BARBOSA, Elyana. Gaston Bachelard: precursor de uma nova epistemologia. In SANT'ANNA, Catarina (org). Para ler Gaston Bachelard: ciência e arte. Salvador: EDUFBA, 2010.

BIAZZI, R. MEC suspende abertura de cursos de Direito e estuda estágio obrigatório. In Bom Dia Brasil [online]. Disponível em http://g1.globo.com/bom-diabrasil/noticia/2013/03/ mec-suspende-abertura-de-cursos-de-direito-e-estuda-estagioobrigatorio.html. Acesso em 30 nov 2015. 
BOBBIO, Norberto. O positivismo jurídico: lições de filosofia do direito. São Paulo: Ícone, 1995.

BUSSINGUER, E. C. de A. Ensino jurídico e aprendizagem significativa: uma tentativa de compreensão da tragédia do direito e da justiça a partir de uma abordagem fenomenológica. In MIGUEL, P. C.; OLIVEIRA, J. F. Estratégias pedagógicas inovadoras no ensino jurídico. V2. Rio de Janeiro: Lumen Juris, 2012. pp. 55-84

CARNAP, Rudolf; NEURATH, Otto; HAHN, Hans. A concepção científica do mundo: o

Círculo de Viena. In Cadernos de História e Filosofia da Ciência, 1986, pp. 5-20. COELHO, Fábio Ulhôa. Para entender Kelsen. 4 ed. rev. São Paulo: Saraiva, 2001.

COMTE, Auguste. Curso de filosofia positiva. Col. Os Pensadores. Trad. Arthur Giannotti. São Paulo: Abril Cultural, 1978.

FELIX, Loussia P. Musse; SANTOS, Aline Sueli de Salles. Demandas profissionais em Direito e avaliação: educação jurídica, competências e sua inserção nas carreiras jurídicas por meio dos exames públicos. In OAB. Desafios rumo à educação jurídica de excelência. Brasília: OAB, 2011.

FERRAZ JUNIOR, Tércio Sampaio. Função social da dogmática jurídica. São Paulo: Revista dos Tribunais, 1980. dominação. 4 ed. São Paulo: Atlas, 2003.

. Introdução ao estudo do direito - técnica, decisão,

FRANCISCHETTO, G. P. P. As tendências pedagógicas e sua utilização no ensino do Direito. In FRANCISCHETTO, G. P. P. Um diálogo entre ensino jurídico e pedagogia. Curitiba: Editora CRV, 2011.pp. 11-33

FREIRE, P. Pedagogia da autonomia: saberes necessários à prática educativa. São Paulo: Paz e Terra, 2010.

GIESELER, M. XXII Conferência Nacional da OAB: em 19 anos, número de faculdades de Direito no Brasil cresceu 778\%. In Portal Exame de Ordem [online]. Disponível em http:// blog.portalexamedeordem.com.br/blog/2014/10/xxii-conferencia-nacional-da-oab-em-19anos-numero-de-faculdades-de-direito-no-brasil-cresceu-778. Acesso em 30 nov 2015.

HART, H. L. A. O conceito de direito. São Paulo: Martins Fontes, 2009. KELSEN, Hans. O problema da justiça. 3 ed. São Paulo: Martins Fontes, 1998. Teoria Pura do Direito. 6 ed. São Paulo: Martins Fontes, 1998.

MARCONI, Marina de Andrade; LAKATOS, Eva Maria. Fundamentos da metodologia científica. 5 ed. São Paulo: Atlas, 2003.

MOTA, Marcus. A teoria dos obstáculos epistemológicos: G. Bachelard entre a epistemologia e a hermenêutica. In SANT'ANNA, Catarina (org). Para ler Gaston Bachelard: ciência e arte. Salvador: EDUFBA, 2010. 
OAB. Brasil, sozinho, tem mais faculdades de Direito que todos os países. Disponível em http://www.oab.org.br/noticia/20734/brasil-sozinho-tem-mais-faculdades-de-direito-quetodos-os-paises, acesso em 30 mar 2016.

OLIVEIRA, J. F. de. Ensino jurídico: história que explica a prática docente. In MIGUEL, P. C.; OLIVEIRA, J. F. de (org). Ensino jurídico: experiências inovadoras. Rio de Janeiro: Lumen Juris, 2010. pp. 01-07.

RADBRUCH, Gustav. Introdução à Filosofia do Direito. Trad. Prof. Jacy de Souza Mendonça. São Paulo: Martins Fontes, 2002.

RODRIGUES, Horácio Wanderlei. Metodologia da Pesquisa nos Cursos de Direito: uma análise crítica. In: XIV CONGRESSO NACIONAL DO CONPEDI, 2006, Fortaleza. Anais do XIV CONGRESSO NACIONAL DO CONPEDI. Florianópolis (SC): Fundação Boiteux, 2005.

SOUSA JUNIOR, José Geraldo de. Educação continuada na docência e a ampliação sistêmica do conhecimento - visão de um jurista. In OAB. Desafios rumo à educação jurídica de excelência. Brasília: OAB, 2011.

STRECK, Lenio Luiz. Hermenêutica e ensino jurídico em terrae brasilis. In Revista da Faculdade de Direito UFPR. Vol. 46, n. 0, 2007, pp. 27-50.

Ensino jurídico e pós-graduação no Brasil: das razões pelas quais o Direito não é uma racionalidade instrumental. In Revista Alcance [online]. V. 16, n. 01. Jan-Abr 2011, pp.

05-19.

Thays, 18, passa na OAB: o rei está nu! Fracassamos! In Revista Eletrônica Consultor Jurídico, 01 maio 2014, disponível em http://www.conjur.com.br/2014-mai-01/ senso-incomum-thays-18-passa-oab-rei-nu-fracassamos, acesso em 30 mar 2015.

VEJA. Brasil tem um advogado para cada 322 habitantes [online]. Disponível em http:// veja.abril.com.br/noticia/brasil/brasil-tem-advogado-cada-322-habitantes, acesso em 09 abr 2016.

WARAT, Luis Alberto. Epistemologia e ensino do direito: o sonho acabou. Vol. II. Florianópolis: Fundação Boiteux, 2004.

Saber crítico e senso comum teórico dos juristas. In Revista Sequência.V. 3, n. 05. Florianópolis, 1982. 